Article

\title{
Why Do Workers Take Safety Risks?-A Conceptual Model for the Motivation Underpinning Perverse Agency
}

\author{
Zuzhen Ji ${ }^{\circledR}$, Dirk Pons'* and John Pearse \\ Mechanical Engineering, University of Canterbury; Christchurch 8140, Canterbury, New Zealand, \\ zuzhen.ji@pg.canterbury.ac.nz (Z.J.); john.pearse@canterbury.ac.nz (J.P.) \\ * Correspondence: dirk.pons@canterbury.ac.nz; Tel.: +64-33-695-826
}

Received: 8 May 2018; Accepted: 8 June 2018; Published: 11 June 2018

\begin{abstract}
Exposure to chronic harm is difficult to manage and prevent in industry. There is a need to better understand the state of mind when workers disregard safety processes and expose themselves to this type of risk. This paper develops a theoretical model of the reason why workers voluntarily expose themselves to occupational health and safety (OHS) hazards. This Risk, Agency, and Safety \& Health (RASH) model proposes that people willingly expose themselves to chronic injuries via a series of risk-taking processes. This causal chain starts with personal motivation and over-alignment with organisational purpose (including impression management). Ideally, that motivation would be moderated by an ability to predict future harm consequences from the task at hand, but that mechanism is weak because it is difficult to predict cause and effect, the consequences are too far in the future, and the opportunities for vicarious learning are few. The motivation then causes misdirected creativity, hence the development of personally novel ways of solving the problem, albeit with greater risk of harm. Perverse agency then sustains actions that exposure the person to harm. Original contributions are the provision of a detailed explanation for risk-taking, and the integration of multiple well-established psychological constructs.
\end{abstract}

Keywords: manufacturing industry; occupational health and safety; agency; motivation; short cuts; risk taking

\section{Introduction}

Industrial occupational health and safety has become increasingly important in the legislative landscape of most countries. Existing methodologies for reducing harm are primarily based on the risk methodology [1], namely the reduction of consequence or the likelihood of harm. This is evident in the hazard assessment methodology and its deviations [2]. The general strategy has focused on avoiding accidents by safety by design of technology, e.g., plant layout design [3], equipment design [4,5], safety system design [6], maintenance design [7], and risk management [8]. Other accidents prevention mechanisms are safety training [9] and signage $[10,11]$. The operator contributions to accidents are included via human error considerations, such as the slip-lapse-mistake-violation categorisation [12]. Procedural failings are represented in bowtie analysis [13,14] and fault tree analysis [15]. However, there is a deeper question as to the state of mind when workers disregard safety processes.

This paper develops a theoretical model of the reason why workers voluntarily expose themselves to occupational health and safety (OHS) hazards. The area under examination in this paper is occupational health and safety in the manufacturing industry. The concept of perverse agency is introduced to explain how workers may self-motivate themselves to take risky short cuts. 


\section{Background Literature}

\subsection{Occupational Health and Safety in Manufacturing Industry Work}

The importance of OHS has changed during recent years, with an increased emphasis on the responsibility of industry to avoid harm to workers. Historically the main focus has been on safety, rather than the health aspect. Safety refers to a prevention of accidents that might immediately lead to harm. In contrast, health refers to long-latency health issues, cumulative harm effects, or chronic harm. The issue is that occupational harm cannot always be attributed to a single or definitive accident, and does not always occur immediately after an event. Unlike an accident, this type of harm may take time to become apparent. There may be delayed onset or persistent symptoms over extended periods. Additionally, some health issues may occur by cumulative hazard exposure [16]. In contrast, the safety perspective is more focused on the immediate harm consequences of accidents.

The World Health Organisation (WHO) describes occupational health and safety as:

'Occupational health deals with all aspects of health and safety in the workplace and it has a strong focus on the primary prevention of hazards. The health of the workers has several determinants, including risk factors at the workplace leading to cancers, accidents, musculoskeletal diseases, respiratory diseases, hearing loss, circulatory diseases, stress related disorders, and communicable diseases, as well as others. Employment and working conditions in the formal or informal economy embrace other important determinants, including working hours, salary, workplace policies concerning maternity leave, health promotion, and protection provisions, etc.' [17].

Some common OHS risks in the manufacturing industries are noise [18], cuts [19], dust inhalation [20,21], chemical exposure [22], and repetitive activities [23,24], among others. Noise at high levels is an example of an insidious health hazard because of the potential for workers to be exposed over long durations. This can cause hearing loss, which can be permanent [25]. Most nations are aware of this hazard and use enforcement, standards, and legislation to protect hearing loss [25]. All the same, the harm persists: WorkSafe New Zealand showed that there were more than 11,000 ear injuries reported in 2014 and most of them were noise-related hearing loss [26].

\subsection{Motivation}

Returning to the WHO definition of OHS above, it is apparent that, in the conventional construct, the causal factors are predominately external constraints of the workplace that are imposed on the worker, and there is little explicit identification of motivations internal to the workers themselves. However, motivation is an important factor in occupational health and safety.

Motivation is a psychological concept and it is used to describe the reason for one's behavior. Expectancy theory is a motivation theory developed by Victor H. Vroom in 1964 [27]. Expectancy theory explains motivation as the combined effect of a chain of three factors: expectancy, instrumentality, and valence [28]. This is typically expressed as:

$$
\text { Motivation }=\text { Expectancy } \times \text { Instrumentality } \times \text { Valence }
$$

Expectancy is the personal assessment that exertion of effort will result in performance. Instrumentality represents the personal thinking of whether that performance will result in reward or punishment. Valence describes the extent to which that reward or punishment is important to the person. If the outcome of motivation is positive, it means that people are happy to do the job.

There are two types of rewards that are used in driving employee's motivation: intrinsic and extrinsic rewards [29]. Intrinsic rewards are psychological rewards, such as verbal rewards or a sense of accomplishment [30,31]. Extrinsic rewards are rewards, such as money, bonuses, holidays, and promotions [29]. Employers select rewards to deliberate drive motivation. This is a widely researched area in the business motivation literature, where the objective is to better understand the relationship between rewards and performance, e.g., [32]. Many industries using this method to drive 
employee's motivation and increase productivity [33], participation [34], and quality of work [35]. However, the same motivational methods may cause workers to over-align with organisational purpose, and they result in stress and fatigue, and hence, increase their risk of harm. Therefore, psychosocial factors are also important at work [36].

\subsection{Mental Health and Motivation}

Mental health is another considerable issue for industry. It is described as the 'psychological state of someone who is functioning at a satisfactory level of emotional and behavioral adjustment' [37]. Mental health problems have negative effects on individual motivation, with real economic consequences, such as decreased productivity. Contributory factors include time pressure, job satisfaction, and workload [38]. Modern legislative frameworks explicitly assign to industry the duty to protect both physical and mental health, e.g., [39], but the safety frameworks are asymmetrically focused on the former.

Existing research in mental health in the context of safety is focused on mental workload [40], effects between mental capacity and work ability [41], loss of concentration and difficulty in cooperating [42], physical behavior outcomes [43], and links to accidents [44,45]. There is a strong relationship between mental health and individual's motivation $[46,47]$.

Additionally, mental health affects motivation. In turn, motivation affects people's decision making [48]. The present paper focuses on motivation, and how it affects workers' approaches to safety. Mental health is not explicitly included here, except as a possible precursor to motivation.

\subsection{Causes of Voluntary Exposure to Risk}

Lack of OHS knowledge can increase the likelihood of exposure. Some workers do not clearly understand the risks in a task, and they cannot anticipate the hazard beforehand. Therefore, it is usually too late for them to devise a treatment or precaution when they notice the harm occurring [49]. Workers with a high OHS awareness are likely to pay more attention to their health and safety, and this makes them more careful at work than other people [50].

Secondly, some experienced workers have a good understanding of the occupation health and safety, but they still accept work with risks and they tacitly consent to unknown safety hazards. Survey results show that $90 \%$ of workers are not afraid to meet challenges at work, even though they know that it will be an unsafe environment or unsafe work practices [50]. It is apparent that workers are willing or inadvertently take short cuts in their health and safety.

Thirdly, management and organisational culture can affect OHS hazard exposure [51]. The reason for an organisation existing is to make a profit, and this has a strong connection to production targets in manufacturing industries. Organisations have to meet their productivity targets, thus they provide incentives for workers to align with economic objectives. The common methods using in labor-productivity improvement are overtime work, and imposing pressure on workers [52]. Consequently, workers have to sacrifice their rest time or increase their productivity, which makes them feel tired, unbalanced, and stressed [53]. Providing rewards is one of the treatments to drive workers' motivation [54,55]. However, it still increases the risk of OHS hazards at work [53]. Therefore, it is easy to make changes in workers' motivation, but this can also leave them feeling anxious or upset.

Poor managerial ethics also has a negative effect on safety and accidents prevention [56]. This may be because some managers cannot identify the OHS problem clearly, simply tell their employees that they are working within a safe situation, and prevent them from questioning the organisation's decisions [57]. Furthermore, organisational culture plays an important role in workers' attitude [58]. This is because of group mentality. This causes a person to behave in a way that is based on others' performance rather than their own [59]. It operates via psychology mechanisms of peer pressure and vicarious learning. Cultures that emphasise manly behavior may, for example, cause workers to avoid wearing ear protection if they feel that it makes them look soft. It is difficult to make changes in workers' perceptions and attitudes about standard safety practices [60]. 


\subsection{Contemporary Issues in Occupational Health and Safety (OHS) Research}

There are many ongoing issues with OHS as applied to industrial work. Firstly, the literature identifies only a few methodologies to optimize health and safety. Most of the research is focused on risk reduction and a limited range of interventions (for example, educating workers and personal protective equipment (PPE)). Secondly, health and safety (H\&S) legislation in many countries requires employers to minimize occupational health loss, e.g., [40], however the long latency of these injuries makes it difficult to detect the damage as it occurs. Additionally, it is difficult to determine which past work period contributed to the harm, and as a result, it is difficult to prevent. Thirdly, there is only limited understanding of the causality for occupational health issues. Workers typically undertake many different activities in manufacturing plants, so it is difficult to attribute harm to a specific cause. Furthermore, it is also difficult to understand why people make short cut actions in health and safety. Finally, most of the attention relating to risk assessment is applied to the safety and the prevention of accidents that lead to immediate harm, with less on health issues, especially on the long-term health. A related problem is that the definitions and methods in monitoring health risks are limited.

\section{Methods}

\subsection{Purpose}

The purpose of this research was to develop a model to explain the causality whereby people take short cuts in personal occupational health and safety. We wished to understand the human factors and the flow of conscious and subconscious decision making that affect hazards exposure.

\subsection{Methodology}

A qualitative methodology was applied to develop the model. We started by examining the literature for relevant constructs in the occupational health and safety literature. We then developed an initial model that sought to describe how workers' motivation affects their actions. This was presented to the annual general meeting of the New Zealand Society of Safety Engineering ('Occupational health in an industrial context-Overview of UC research project', 25 January 2017, IPENZ, 50 Customhouse Quay, Wellington, New Zealand) and discussed by a group of eight professional engineers with expertise in safety engineering. They provided a critique of the model, identifying areas that were well represented and also those that were under represented. From this early work arose the idea of perverse agency (described below). These discussions were used by the authors to further refine the model.

Subsequently, there was an individual discussion with an engineer from a construction firm, and this resulted in further refinements. We then examined the Pike River Mine disaster [61], from which we extracted additional principles of how incentivisation could affect workers motivation towards unsafe acts. From this arose an element in the model relating to over-aligned with organisational purpose.

The next stage in the development of the model was the adoption of several constructs from psychology and organizational behavior, e.g., personality, dark triad, and motivation theory. Doing this grounds the model in the wider literature. The psychological constructs themselves are not critically evaluated here; rather, it is the integration of them into a wider model that is new. Consequently, the constructs are defined at first usage in the results, rather than being described in the literature review above.

Moving to completion, we then developed the model to explain why workers might appear to willingly forgo their own safety to complete a task. Throughout the development, we applied a system engineering methodology. Specifically, we represented the ideas as a flowchart with proposed causal mechanisms, and we continuously revised it to ensure coherence in what was being represented. We anticipated what cognitive mechanisms might be involved, and where they might be positioned in the flow of decision-making. 


\section{Results: Risk, Agency, and Safety \& Health (RASH) Model}

\subsection{Overview Model}

We propose that workers approach H\&S decisions in a sequential manner, starting with an evaluation of the task at hand. They then apply their personal agency to execute the task, and an H\&S outcome emerges. This simple linear model is shown in Figure 1.

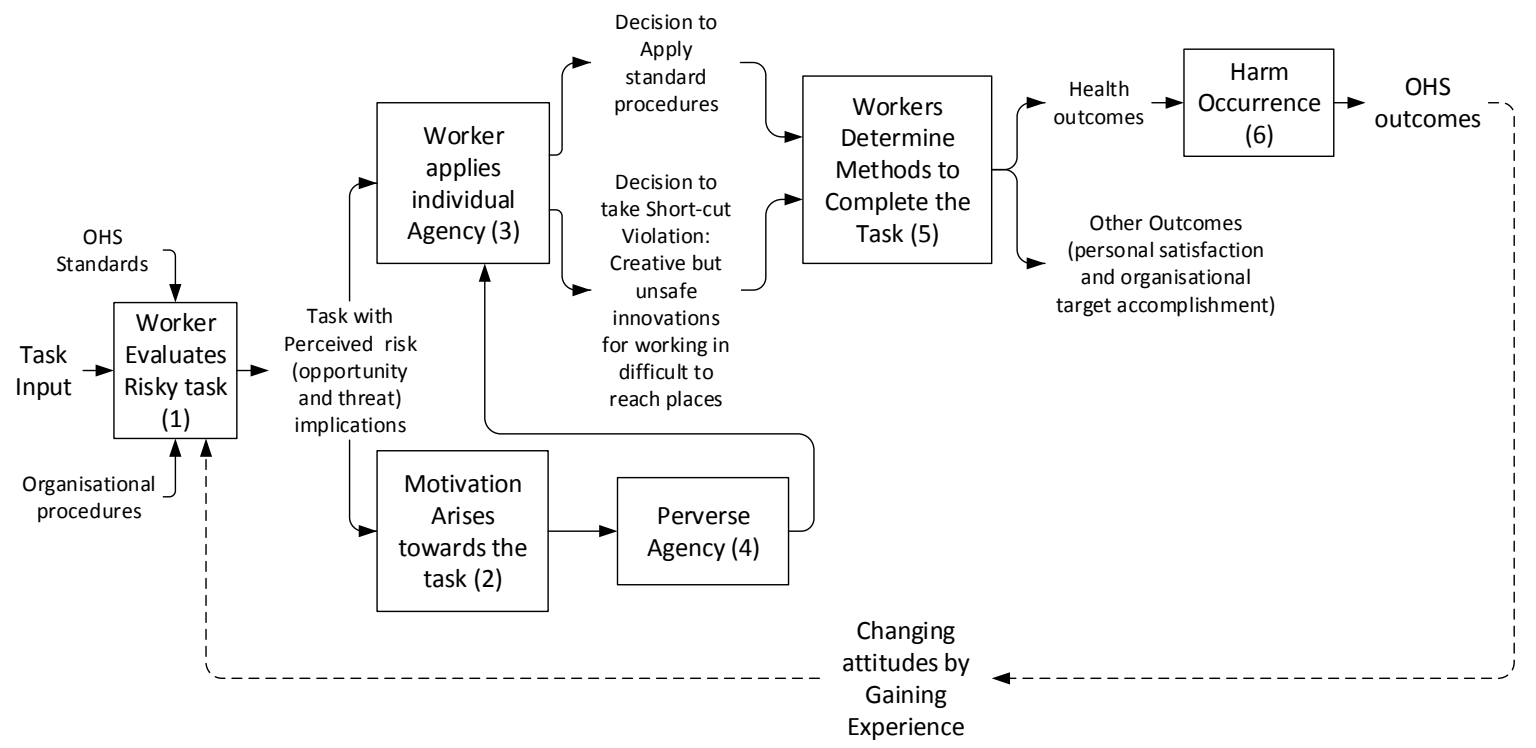

Figure 1. Risk, Agency, and Safety \& Health (RASH) Model.

However, the process is complicated in several ways. Firstly, there are situational variables in the form of OHS standards and standard operating procedure that will affect the worker's decision. Secondly, there are management and organisational culture variables that will shape the response. Thirdly, there is learning that occurs: people gain experience and this influences their future decision making. The result of this process is that agency is applied in positive or negative ways. Later, we propose that the antecedents for perverse agency primarily occur early in the process, at the stage, when the worker is evaluating the risky task.

We term this the RASH (Risk, Agency, and Safety \& Health) model as it encompasses these various effects. Additionally, it proposes mechanisms whereby workers make imprudent decisions, hence perverse agency.

The following sections elaborate on this concept by progressively detailing each process.

\subsection{Process 1: Worker Evaluates Risky Task}

We propose that workers take a pragmatic approach to their initial evaluation of risks within the task at hand. Specifically, we propose the existence of two key factors in the decision-making. The first dimension is the perceived task novelty, wherein the task is evaluated for the degree to which it is well-defined or novel. The second is the perceived residual risk, which is the worker's evaluation of the extent to which existing treatments are effective at preventing the risk. We propose that these factors interact in the following manner. 


\subsubsection{A: Low Task Novelty_Low Residual Risk}

For a safety system that is within control, i.e., functioning effectively, the task is routine (has been standardised) and the existing treatments (e.g., procedures, PPE) are effective. Therefore, the worker is not exposed to unreasonable risk.

\subsubsection{B: Low Task Novelty-High Residual Risk}

In situations where the safety system has inadequately assessed the risks, the treatment might be ineffective, even for routine tasks. This arises because the organisation or the worker has not validated that the treatment is indeed effective. Thus, a larger residual risk is presented to the worker than expected. The worker undertakes the task naively and this results in inadvertent exposure to known hazards. It is worth noting that, in terms of legislation, it is the duty of the organisation and its executives, not primarily the worker, to validate that the treatments are effective.

\subsubsection{C: High Task Novelty—High Residual Risk}

Another situation is where the tasks are perceived to be novel, and the worker correctly identifies that the existing treatment does not fully control the threat. Thus, there is a known and significant residual risk. The work requires additional safety precautions and treatments to deal with the new risk. At this point, the worker has a choice: to refrain from doing the task, or to proceed with personal acceptance of the risk. The latter choice results in conscious exposure to the hazards.

\subsubsection{D: High Task Novelty-Low Residual Risk}

The fourth situation is that the worker correctly perceives the task to be novel, but it fails to recognise the new risks therein. We anticipate that this situation arises from a lack of situational awareness, ineffective hazard assessment, poor training, or failure to anticipate cause and effect. Thus, the worker fails to perceive the new hazards in the situation, and persists with work procedures that are inefficient proof against those hazards. This results in ignorant exposure to new hazards. The ideal organisational practice is that the resulting near-accidents will be reported, and will result in the eventual re-assessment of the hazards in the situation and better future protection.

This proposed causality is summarized in Figure 2. The diagram represents the branches of decision-making made by the worker in the various situations. It also shows the proposed causal mechanisms (arrows entering under the actions) and the constraints on those actions (arrows entering above). The numbers in circles represent call-outs to locations in other diagrams.

We also propose a further simplified model, which is one that ignores the causality and simply represents the outcomes as a function of the inputs. For this model, we assume that the two input dimensions are orthogonal, resulting in a $2 \times 2$ matrix of outputs, see Figure 3 .

It is evident that significant numbers of people do make the choice for conscious exposure to the hazards (output C). In the next part of the model, we speculate on the motivations for this behavior, and we introduce the term 'perverse agency' to describe it. 


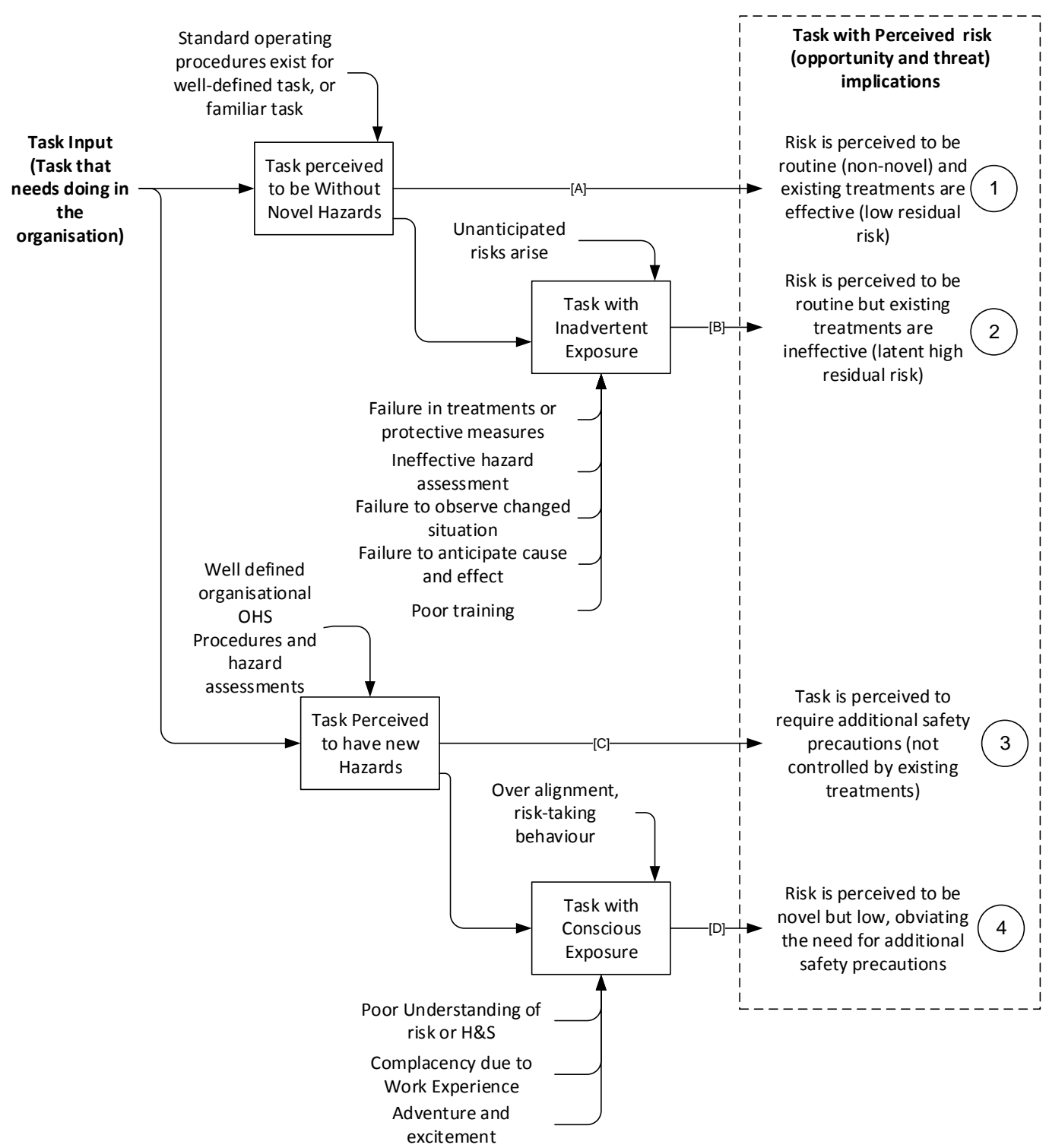

Figure 2. The Worker Evaluates Risky Task Model.

\begin{tabular}{|c|c|c|}
\hline Novel Task & $\begin{array}{l}\text { D } \\
\text { Risk is perceived to be } \\
\text { novel but low, obviating } \\
\text { the need for additional } \\
\text { safety precautions }\end{array}$ & $\begin{array}{c}\text { C } \\
\text { Task is perceived to } \\
\text { require additional safety } \\
\text { precautions (not controlled } \\
\text { by existing treatments) }\end{array}$ \\
\hline \multirow[t]{3}{*}{ Routine Task } & $\begin{array}{l}\text { A } \\
\text { Risk is perceived to be } \\
\text { routine (non-novel) and } \\
\text { existing treatments are } \\
\text { effective (low residual risk) }\end{array}$ & \begin{tabular}{|c} 
B \\
Risk is perceived to be \\
routine but existing \\
treatments are ineffective \\
(latent high residual risk)
\end{tabular} \\
\hline & $\begin{array}{l}\text { Existing Effective } \\
\text { Treatment }\end{array}$ & $\begin{array}{l}\text { Ineffective } \\
\text { Treatment }\end{array}$ \\
\hline & - Low Risk & - High Residual Risk \\
\hline
\end{tabular}

Figure 3. $2 \times 2$ Risk Task Matrix. 


\subsection{Process 2: Motivation Arises towards the Task}

We propose that motivation arises before workers make any H\&S short cuts, see Figure 4. Specifically, we propose as a first approximation that intrinsic and extrinsic motivation operate somewhat independently of each other. The intrinsic factors are internal personal choices, whereas the extrinsic factors arise in the organisational environment that surrounds the worker. However, we also propose that the separation is not absolute, and we identify pathways whereby these factors mutually affect each other.

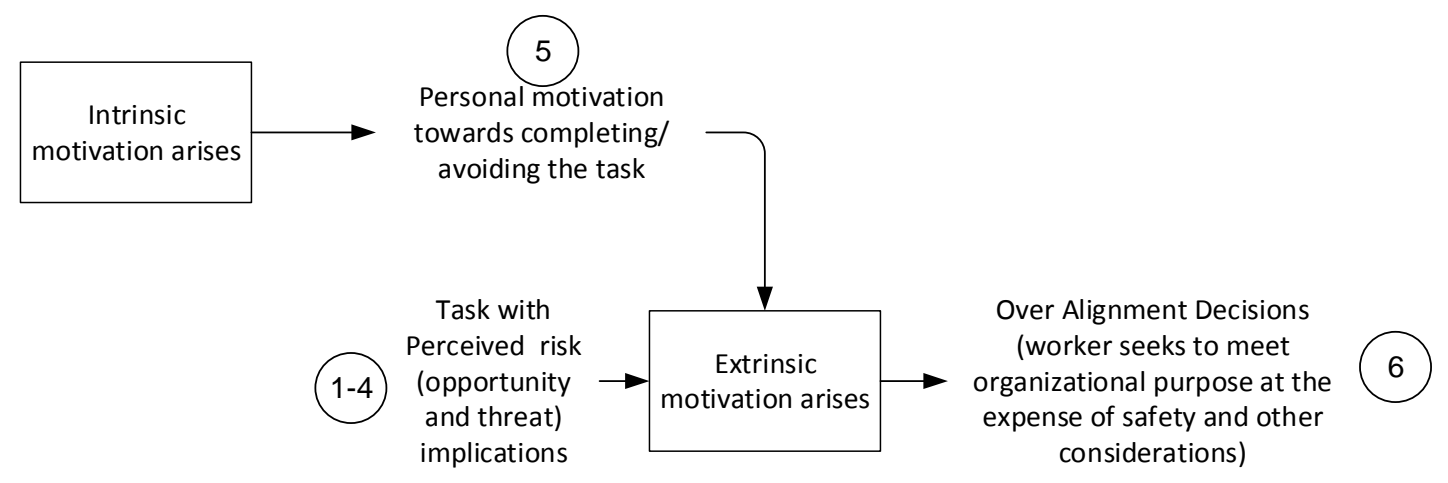

Figure 4. Motivation Arises towards the task.

\subsection{Intrinsic Motivation}

Intrinsic motivation (IM) refers to internal or personal motivations that can affect one's behavior [32]. In this model, IM affects work attitude and personal valance (attitudes towards reward and punishment). We propose that there are five main characteristics within IM. These are: A: Personality (especially Conscientiousness), B: Personal Worldview, C: Self-efficacy, and D: Dark Triad. We propose that there are four main routes that can affect intrinsic motivation and result in personal choice in safety behaviors, as per the explanation below and the representation in Figure 5.

\subsubsection{A: Personality}

Personality refers to enduring individual styles of behavior. This affects how people respond or behave in situations, and it can effect performance [62]. The five factor model (FFM), also known as the Big 5, is the dominant description of personality [63]. The factors are Openness, Conscientiousness, Extraversion, Agreeableness, and Neuroticism (OCEAN). Of these factors, we propose that conscientious is the key characteristic in the safety situation, and we suggest it contributes to a positive work ethic. Conscientiousness refers to a cluster of attributes that include carefulness, hard-working, vigilance, reliability, dependability. Generally, conscientious people are self-disciplined, and prefer planning rather than spontaneous behavior. We also propose that conscientious people are more likely to accept a task with unknown risk, because their internal sense of responsibility can affect one's agency and then can be over-aligned with the organisational purpose, see following Section 4.7, Process 4. This is consistent with the literature, where conscientiousness is specifically associated with health and safety attitudes [64] and workplace performance [55,65]. The five-factor model of personality was deliberately designed to avoid pejorative meanings. Consequently, the extremes of all its scales are intended to be non-condemnatory. The behaviours it describes are neither good nor bad-instead, they are merely styles of interaction. However, the reality is that people do behave in selfish ways, and this needs to be included.

\subsubsection{B: Personal Worldview}

Personal worldview is another attribute that effects the worker's motivation towards safety. A worldview is the totality of a person's perspective on the world and the values that they seek to 
embody in their own life. Belief systems are the mental constructs that individuals and groups create to make sense of themselves and their spiritual place in the world. They provide an existential postulate. They are based on faith-not necessarily religious. The world view is coherent to the person who holds it—its makes sense to them. It is also strongly held, in that people will not easily change their view. Individuals within a culture share elements of the same world view.

No amount of information will change a worldview. They are deep seated beliefs that are linked to personal identity. Conflict can arise between people with different world views. The conflict is about the values. Personal value system is structured by one's world view; and, it tells a person what is good, important, and desirable. Consequently, in the safety situation, it provides a mechanism that creates an intrinsic perception of right vs. wrong regarding safety, see Figure 5 and route B1 therein.

Furthermore, we propose a second route whereby personal worldview affects attitudes towards safety. This is via the value systems of the worldview affecting the valence; therefore, the extent to which a particular outcome has value to the individual, see Figure 5 and route B2 therein.

It is expected that these personal values will be affected by upbringing, environment, ethnicity, culture, etc. This is consistent with others in the literature who have proposed that personal value systems play an important factor in personal behavior for health and safety [66]. There are many situations in societies where these personal worldviews cause people to accept significantly higher safety risks than usual, a common example being war. The effect is also evident in industry, and results in workers making personal sacrifices to improve the organisational outcomes, examples being a Chinese oil drilling worker called Wang Jinxi who achieved hero status by jumping into the mud pool of an oil drilling well to stir the mud with his body, and hence, keep the well operating. This example of positive work attitude continues to affect and reinforce the Chinese value system and worldview about work ethic. Consequently, we propose that worldview affects the personal assumption or the avoidance of risk.

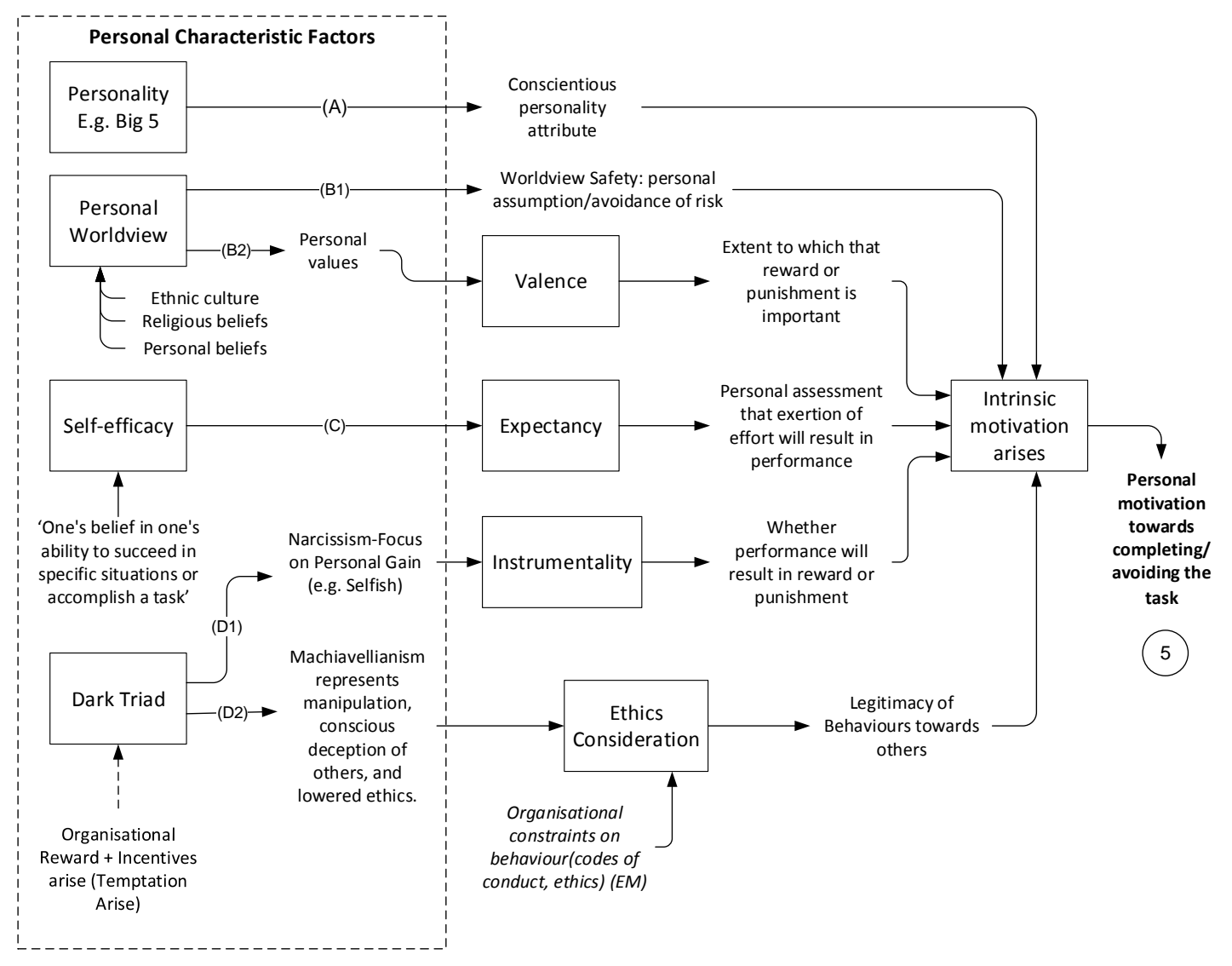

Figure 5. Intrinsic Motivation Model. 


\subsubsection{C: Self-Efficacy}

Self-efficacy is the confidence in one's own ability to achieve intended results [67]. As such, it refers to a personal approach towards problem-solving and persistence at a difficult problem, rather than merely self-confidence (which may be potentially misplaced). It has a positive effect on expectancy, general decision making [68], and work engagement [69]. The attribute is also associated with internal locus of control. Self-efficacy is believed to be developed by personal experiences and the external social factors that accompany them (such as encouragement and social learning) [66]. The role of self-efficacy on safety has been noted in the literature, and has, for example, been found to correlate with safety behaviours of pilots [70] and medical doctors [71]. There is also evidence that the locus of control is associated with safety behaviours for truck drivers [72]. It has been shown self-efficacy regarding safety in a steel plant is associated with several organisational factors relating to team communication and supervision [73]. It is also possible that workers take risks as part of impression management-as part of a need to present themselves positively to others, and hence undertake risk-taking activities. We propose that self-efficacy affects motivation directly via the expectancy route.

\subsubsection{D: Dark Triad}

In the present model, the selfish attributes are included using the Dark Triad of personality. The attributes are: Machiavellianism, Narcissism, and Psychopathy [74]. These represent different aspects of malevolent selfishness, and they are all associated with manipulative actions to further their own advantage at the expense of others. Machiavellianism represents manipulation, conscious deception of others, and lowered ethics. Narcissism is characterized by egotism and "excessive love for one's self, feelings of superiority, attention seeking, and exploitativeness in relationships with others" [75]. Psychopathy refers to callous behavior towards others, and can include impulsivity and low remorse [75]. The Dark Triad has previously been applied primarily in the psychology literature, and it is used to explain situations, such as bullying [76] and aggression [77]. Also, the attribute of sensation seeking, which might be considered as another aspect of narcissism, has been associated with risk-taking in skateboarding [78]. The general concept of the Dark Triad has not previously been applied to safety considerations. We proposed that personal dark triad can have an effect on instrumentality. This is because people may balance the rewards and punishment before making an action. Specifically, we propose that the Narcissism factor increases the Instrumentality of the motivation (pathway D1 in Figure 5). Also, that the Machiavellianism factor affects ethical considerations, as elaborated below (see pathway D2, Figure 5).

\subsubsection{E: Ethical Considerations}

Ethical considerations are the moral constraints that organisations set on the behavior of their members. Ethics may exist independently on any personal worldview or religious belief. Ethics internally limits a person to avoid actions that would cause harm to others at work. It provides a judgement mechanism that constrains decision-making in order to preserve the well-being of people. We propose that it primarily acts in the interests of others, and it has a weaker effect regarding self. Consequently, it acts contrary to the selfish decision-making priorities of the dark triad. The intersection of ethics with H\&S is a developing area within the literature [79]. Codes of ethics for the engineering profession often include a duty of care for the H\&S of others [80]. Likewise for other professions. Organisations, especially government departments, may have codes of conduct for their staff, although this is not universal. However, workers are not usually covered by codes of ethics. Consequently, workers may not be subject to an explicit ethical code, though they do still have their own personal moral considerations. These may be based on their culture, religion, and worldviews. In the present model, we propose that ethical considerations include the self-assessment of the legitimacy of behaviours towards others, and hence moderate the Machiavellianism. 


\subsection{Extrinsic Motivation}

Extrinsic Motivation, defined as the motivation that effected by external factors that arise outside of the individual. Extrinsic Motivation is virtually opposite to Intrinsic Motivation. In this context extrinsic motivation (EM) refers to the external factors that are caused by the work environment. These arise outside of the individual, though they interact with and recruit aspects of intrinsic motivation. We propose the following model of how organisations affect the motivation of workers, see text below and Figure 6.

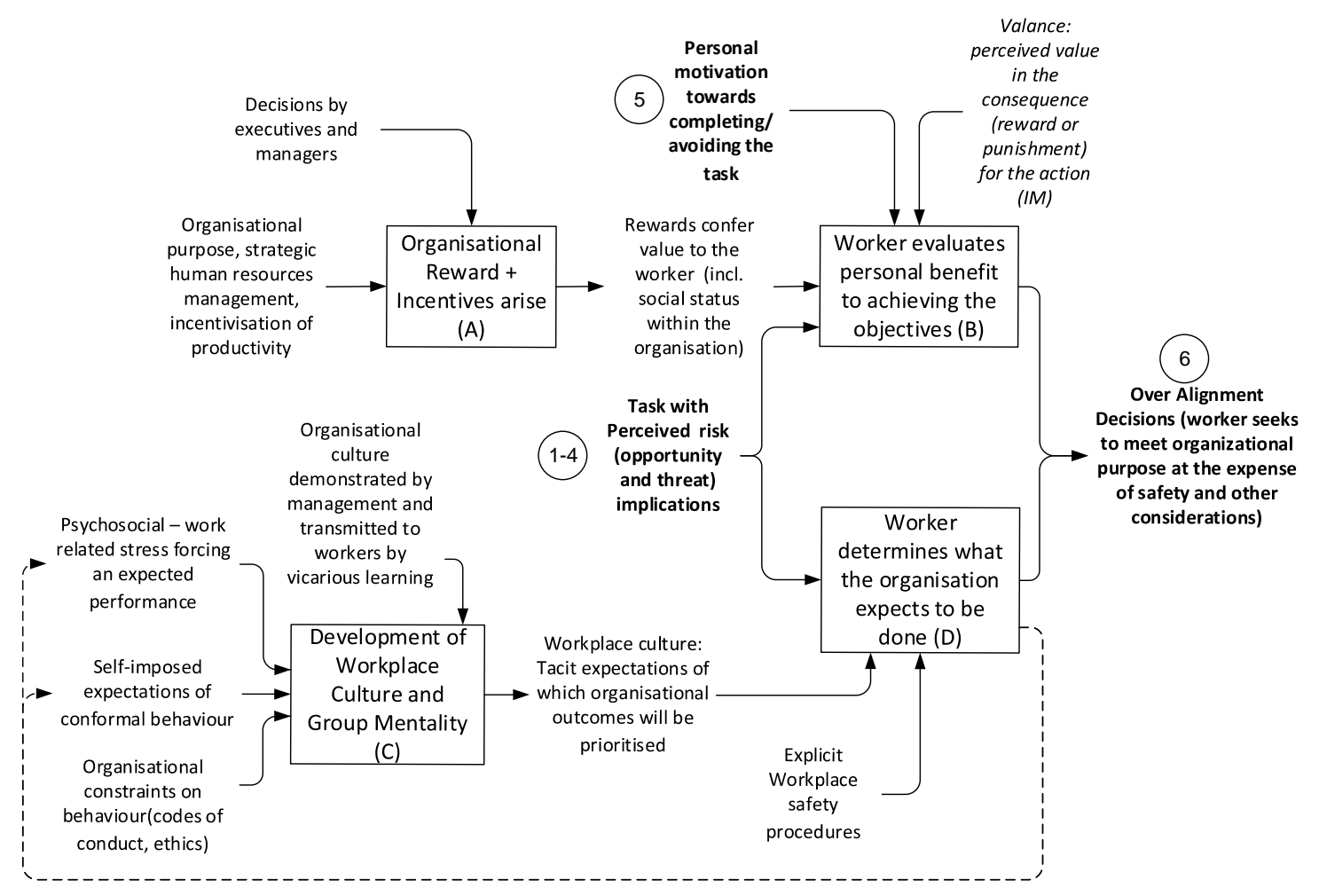

Figure 6. Extrinsic Motivation Model.

\subsubsection{A: Organisational Reward and Incentives}

Organisations exist to fulfil a purpose, and executives and managers make decisions that advance that purpose. The mechanisms used are strategic human resources management, and incentivisation of productivity. These can be affected by external rewards, such as remuneration, extra vacation, and promotion. These rewards confer value to the worker, including social status within the organisation.

\subsubsection{B: Worker Evaluates Personal Benefit to Achieving the Objectives}

Given a Task with its perceived risk (opportunity and threat) implications, the worker considers the personal rewards that the organisation is offering for completing the task, and evaluates the valance thereof. Therefore, the intrinsic and extrinsic motivational factors intersect at this stage. This, we propose, is the first factor that determines the extent to which the work aligns with the organisational purpose. Over alignment occurs when the worker seeks to meet organisational purpose at the expense of safety and other considerations.

\subsubsection{C: Development of Workplace Culture and Group Mentality}

Workplace culture and group mentality affects peoples' behavior generally [81,82], and it is known to affect their attitudes towards safety in particular $[83,84]$. This may occur via peer group pressure [64]. 
Recent research has identified that the creation of a safety-oriented culture requires training [85], systematic organizational processes [86], commitment from management [87], responsiveness to new conditions [88], and national efforts [89]. However, safety culture is difficult to define [90], difficult to measure [91,92], and the relationships between safety climate and safety behavior are not straight forward $[93,94]$.

We propose that group mentality and other developments of workplace culture may have effects on what the organisation implicitly expects to be done, especially its organisational targets. A positive safety culture is proposed to be one that generates belief in workers that accidents are preventable if personal agency is applied. This is related to the concept of causal attribution [95], which in turn, is related to error disclosure [96].

We propose that safety culture is created and demonstrated by management, and is transmitted to workers by vicarious learning (observing how the organization actually behaved in the past). A psychosocial factor is anticipated whereby work related stress forces the individual into an expected performance. Self-imposed expectations of conformal behavior are proposed to contribute to a collective culture, even if that culture is not explicitly articulated. There can also be explicit organisational constraints on behavior (e.g., codes of conduct, ethics). Consequently, the workplace culture provides tacit expectations of which organisational outcomes will be prioritised.

\subsubsection{D: Worker Determines What the Organisation Expects to Be Done}

Workers are presented with a task for which they have a perceived risk. We propose that they determine their personal course of action by balancing tow considerations: the explicit workplace safety procedures (e.g., the need to wear PPE), and the tacit expectations organisational priorities via the organisational culture. In a negative situation this may involve the worker determining that the organisation values productivity more than say safety, even if it has explicit safety systems. In a positive situation, the worker would value safety as an equal priority to productivity, and this might mean doing the task slower (hence, lower productivity) to preserve the safety priority. It is not only the presence of safety protocols and provision of PPE that is important-there also needs to be a culture that prioritises safety equally [97] with other organizational objectives [98], rather than relegating safety to a secondary consideration. Organisations need to consciously work on developing positive safety culture [99] (see also above). Safety nudges may also be useful [100], although this is a developing field.

\subsubsection{E: Alignment Decisions}

Finally, we propose that the worker make a cognitive calculation that combines the perceived personal benefits (B) and the expectations of what action is expected from the organization (D). This calculation may not even be conscious or explicit. The adverse outcome that potentially arises is one of over alignment, where the worker seeks to meet organizational purpose at the expense of safety and other considerations.

\subsection{Process 3: Workers Determine Approach}

We propose that after evaluating the risk in a task (process 1), workers determine their approach to the task. This is primarily a decision process, hence one of personal judgement. The decision may be made consciously or subconsciously. Two main outcomes are anticipated: A decision to apply standard procedures, or to take short cuts. The latter are violations: Creative but unsafe innovations for performing the work. The proposed inner workings of this decision are shown in Figure 7 and are described below. 


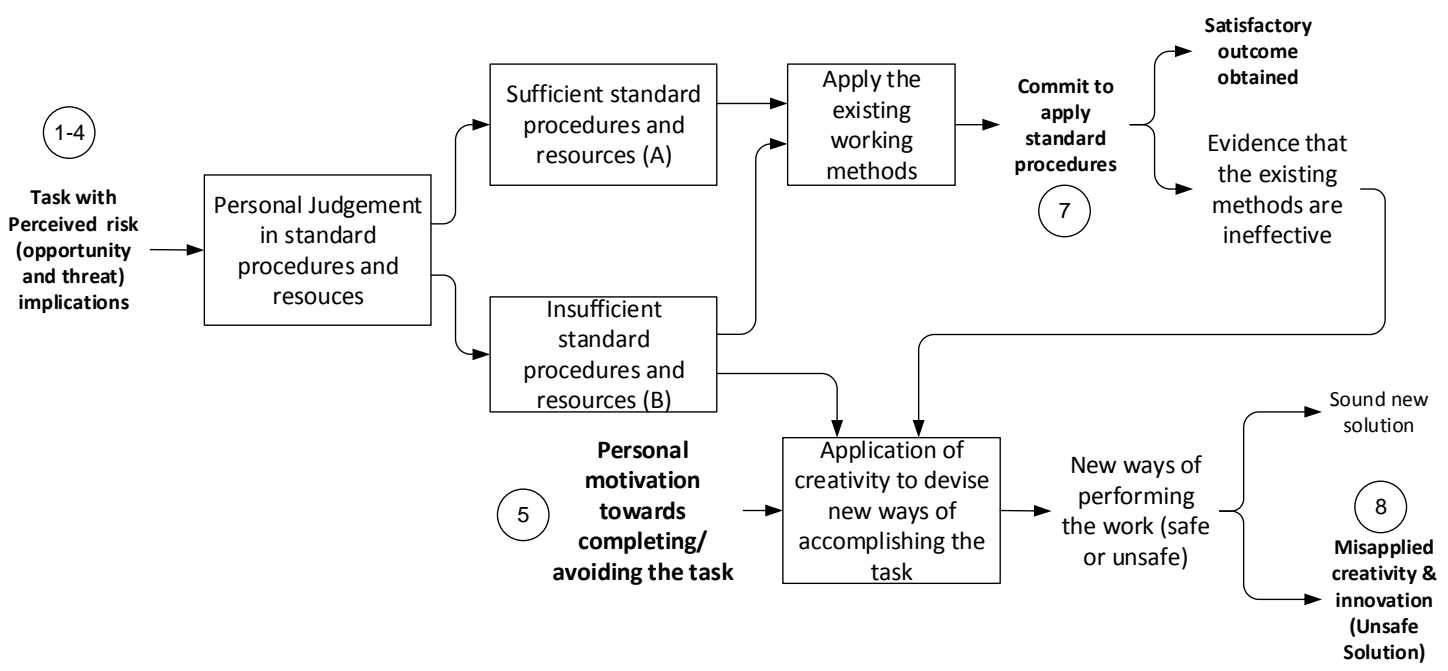

Figure 7. Workers Determine Approach.

\subsubsection{Personal Judgement}

First, we propose that personal judgement is a key factor. In this context, we propose that judgement refers to the ability to identify the multiple alternative solution paths that might exist, the ability to select between these paths based on the benefits and detriments of each in the situation, and the ability to explain and justify their choice. Part of judgement is therefore the ability to adapt to different situations, and to recognize that certain solutions have the potential for adverse outcomes in specific situations. People lack judgement if they fixate on one solution path, irrespective of its appropriateness in the situation.

\subsubsection{Resource Determination}

As a consequence of the application of judgment, the worker makes a decision and this commits them to a subsequent process of evaluating whether their course of action is sufficiently provided with procedures and resources.

\section{A: Sufficient standard procedures and resources}

In this situation, we propose that the current standard procedures and resource can be trusted and the worker believes that they are functioning effectively. Therefore, the worker commits to apply these existed working methods to complete the task.

B: Insufficient standard procedures and resources

In this situation the worker deems there are insufficient standard procedures and resources. Then, the worker may apply those procedures anyway and hope for a favourable outcome. Alternatively, the worker may apply creativity to devise new ways of accomplishing the task. We propose that this occurs when there is personal motivation towards completing/avoiding the task, or the procedures are deemed to be insufficient, or they have previously been shown to be ineffective. Importantly, the outcome may be safe or unsafe.

\subsection{Process 4: Perverse Agency}

Bandura's theory of self-efficacy describes a person's belief in their ability to achieve goals [101, 102]. Agency, per Bandura's concept $[103,104]$, is that people commit their effort in a deliberate way to achieve goals that they have anticipated and have confidence in their ability to succeed. This has developed into a broader construct, which is referred to as sense of agency, personal agency, or human agency. It may also be related to Vroom's Expectancy theory [27]. For example, expectancy has been theorized to have a direct effect on self-efficacy judgments [105]. 
Personal agency is a positive feature of human tenacity [106], but we propose that it has the potential to be recruited to perverse outcomes, i.e., the sense of commitment may be directed towards doing an action that is unwise. This contrasts with the literature, wherein agency is seen as a positive attribute. We do not deny the positive aspects of agency, but propose that it can be directed negatively towards the completion of acts that should not have been done, hence perverse agency. We define it thus:

Perverse agency is application of poor judgement whereby the protagonist persists (by showing decisiveness, action, and commitment) with an unwise course of action and willing assumption (personal acceptance) of risk that others would consider unreasonable, to achieve what they feel is a good objective.

This idea is potentially applicable to many different areas of human decision-making. In the safety context, we propose that process involves the following contributory activities, as described below and represented in Figure 8.

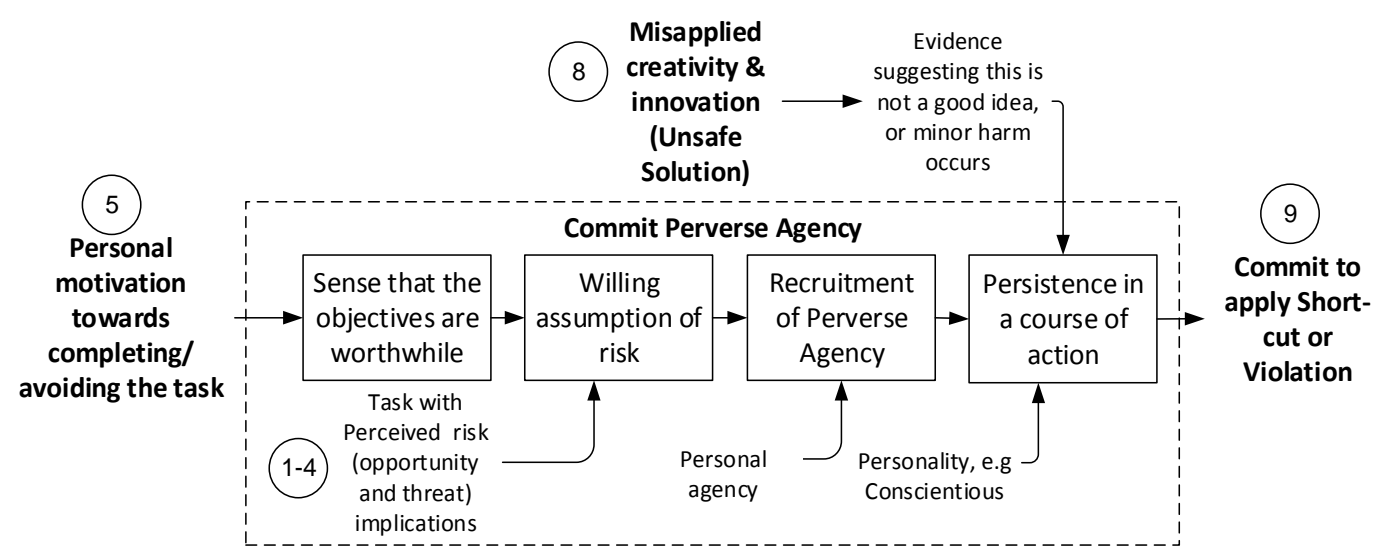

Figure 8. Perverse Agency and Over Alignment Model.

Firstly, a worker has a personal motivation towards completing (or avoiding) a task (see Intrinsic motivation above). Included here is the sense that the objectives are worthwhile to achieve. This is followed by a willing assumption of risk, which in turn, is informed by the prior judgement of the risk inherent in the task (see Process 1 above). Unsafe actions are therefore proposed to be preceded by errors in judgement, wherein either the objectives are over-valued, or the threats are under-appreciated.

The next stage is the commitment of personal agency to attempt to achieve the outcomes decided in the previous stage. Personality is proposed to be involved in perverse agency, via the conscientious personality characteristic [63]. Conscientious workers are reliable, and they desire to complete a task well. They also wish to persistence in a course of action until they finish the job. They may be more loyalty to their employers or organisation. These characteristics make conscientious workers not afraid to accept challenges at work. In the case of hazards, they may prioritise work accomplishment rather than safety, or even consciously take actions that are personally hazardous for themselves for the sake of completing the work.

This recruits a continuation of agency in that the worker persists with the course of action despite disconfirmatory evidence, i.e., evidence suggesting this is not a good idea, or the occurrence of minor personal harm. There may also be an element of misapplied creativity and innovation, in which the worker finds an unsafe but expedient solution (see Process 3). Furthermore, we propose that workers may be inaccurate judging their ability, i.e., their self-efficacy may be unreasonably inflated. This may be because of their excessive expectancy in the outcomes [107].

The end result is that the worker commits to applying a short cut or violation. This is related to, but not identical to assumption of risk (risk-taking). With the assumption of risk, the worker accepts 
a known risk [108], but in the more generalized situation of perverse agency the worker does not necessarily consciously think about the risk, neither the long term consequence nor the likelihood thereof. The personal efficacy suppresses such considerations.

\subsection{Process 5: Worker Executes the Task}

The "Worker executes the task process" model (shown in Figure 9) describes what the workers do after they commit to do a risky task.

The first situation is that workers refuse to do the task. This is because the detriments are unacceptable relative to OHS standards and regulations. However, to complete the work, managers and supervisors may then try to find some new methods in order to reduce the risk. This may result in effectively returning to Process 1 , i.e., the start of the model.

Another situation is that workers accept to do the task and they are willing to be exposed to the residual hazards. In this situation, workers may use safe procedures or engage in short cuts, depending on their decisions earlier in the process (see Process 3).

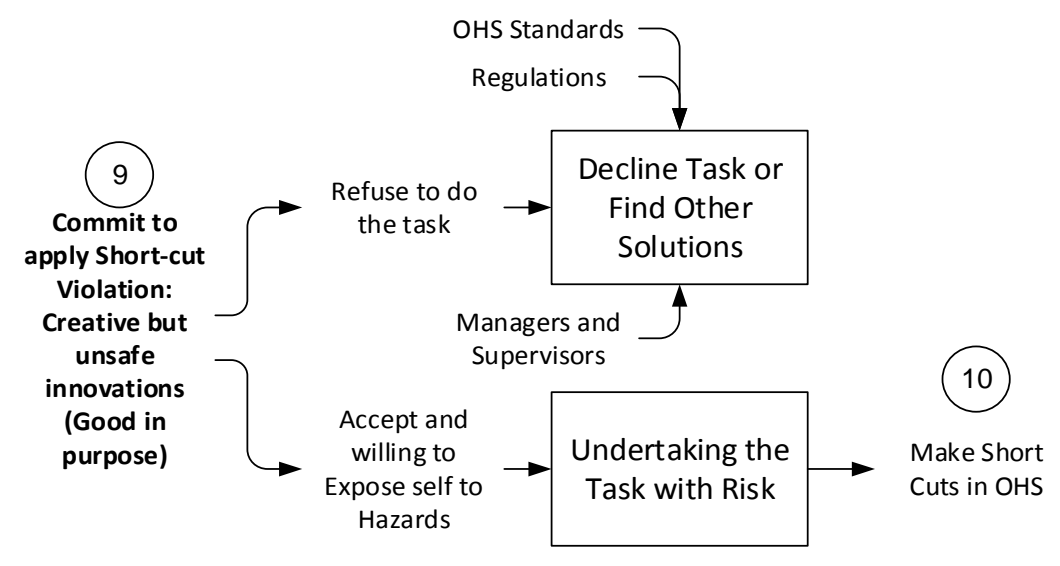

Figure 9. Worker executes the Task Process.

\subsection{Process 6: OHS Outcome}

The final OHS outcome model illustrates the process from harm occurrence to recovery, see Figure 10. Here, we are particularly interested in representing the chronic harm condition, and its relationship to the assumption of risk, perverse agency, and misapplied creativity of the previous stages. Two pathways are used to address the different situations when harm occurs to the human body.

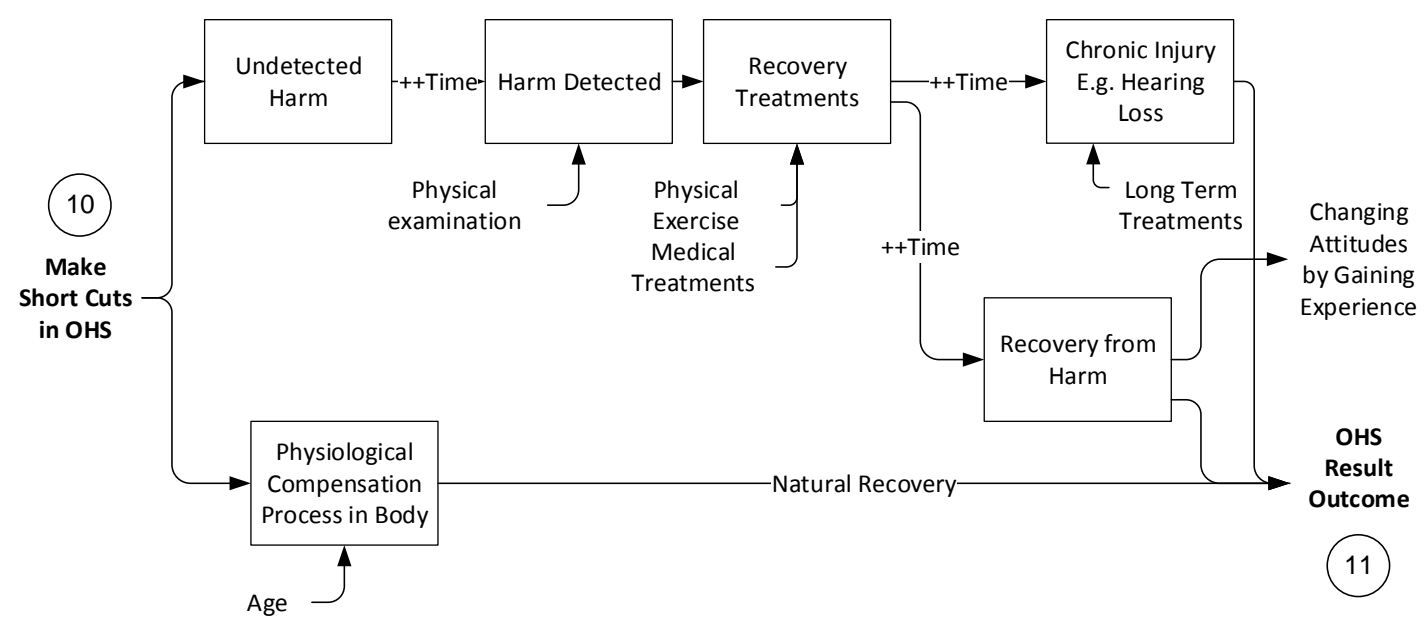

Figure 10. Occupational Health and Safety (OHS) Outcome Process Model. 
The first situation is that natural recovery takes place, and the person recovers full functionality. The worker may not even feel the effects of the injury if the recovery process is faster than the damage inducing mechanisms. The ability for the human body to heal is dependent on age; thus, a degree of risk-taking may be more tolerable for younger than older people.

The second, and more general, situation is that the harm accumulates, often without initial detection. The harm may occur by cumulative exposure (e.g., to noise or chemical compounds), or have a period of latency before symptoms develop (e.g., carcinoma). Subsequently, some time later, people detect their health problem, thus chronic harm/injuries arise. Frustratingly, for prevention efforts, the long latency often means that (a) enduring harm is already done and it is too late to apply prevention or to desist from performing the tasks, and (b) it is not always possible to explicitly identify the original injury mechanism, offending task, or place of work. The latter has the further consequence that the industry does not get timely feedback that certain tasks are unreasonably harmful, i.e., the continuous improvement loop is not closed, and furthermore, the person may not qualify for workers' compensation or free healthcare.

Examples of these chronic injuries include musculoskeletal disease, loss of hearing, and persistent pain. People with chronic injuries may or may not have access to medical treatment, depending on their personal financial situation and the extent of public medical coverage. Chronic injuries tend to reduce peoples' ability to work, and hence reduce income. With time, some people recover functionality, some only partially, and others not at all. At the same time, people are getting older, and natural regenerative healing mechanisms are slower, and other age-related health issues arise to complicate the situation.

Chronic injuries can be seriously debilitating in developing countries, the poor, and the elderly. Furthermore, chronic injury can contribute to anxiety and psychological poor health [109]. People who suffer a chronic injury may have a significant decrease in their quality of life (QOL). There are instruments to measure this loss [110].

Those who do recover and are young enough to still be in employment may find themselves exposed to the same health and safety hazards again. Ideally, their experience of poor health may cause them to be more attentive to their work practices. This is illustrated by the feedback loop in Figure 2. We expect that many workers, especially those who are young and have not experienced medical incidents of any kind, are unable to predict the health consequences of their perverse agency. They do not feel any immediate harm from performing the task, and they are unable to anticipate how it may affect them when they are older. They may even be emboldened to perform risky tasks for the sake of gaining social esteem within the work group. They do not necessarily learn vicariously from seeing how chronic injuries adversely affect the quality of life of older people. Sometimes, those older people are not even in the workplace any longer, so that there is no obvious connection between the present task and the chronic injuries.

\section{Discussion}

\subsection{Summary}

In summary, this Risk, Agency, and Safety \& Health (RASH) model proposes that people willingly expose themselves to chronic injuries via a series of risk-taking processes. This causal chain starts with personal motivation and over-alignment with organisational purpose (including impression management). Ideally, motivation would be moderated by an ability to predict future harm consequences from the task at hand, but that mechanism is weak because it is difficult to predict cause and effect, the consequences are too far in the future, and opportunities for vicarious learning are few. The motivation then causes misdirected creativity, hence the development of personally novel ways of solving the problem, albeit with greater risk of harm. Perverse agency then sustains actions that exposure the person to harm. 


\subsection{Original Contributions}

This work makes several novel contributions. Firstly, it offers a finer-resolution explanation of risk-taking activities in the organizational context. It explains the causality whereby people compromise their personal occupational health and safety. It does this by combining new and old concepts. It incorporates several well-established elements of psychology, namely motivation theory, personality, worldviews, self-efficacy, locus of control, dark triad, and ethics. It also uses the concept of organisational alignment, which is from strategic human resource management (SHRM) and organizational behavior (OB) more generally. Therefore, a second contribution is that these multiple disparate concepts have been integrated into a holistic model.

Several of the specific elements in this model are believed to be original. These include the proposed relationship between novelty and the risk perceived in a task (see the $2 \times 2$ matrix of Figures 3 and 4). Also, the concept of perverse agency has not previously been identified, although the agency of itself is a long-standing concept.

Existing models of harm causation include the following.

Domino theory [111] — This was developed by H.W. Heinrich in 1931 and proposed that accident happens in a sequence like dominoes knocking each other. He also described the cause factors to be social environment and ancestry, fault of the person, and unsafe acts [112]. In contrast, the RASH model focuses more on workers' motivation and decision making. Additionally, RASH includes more factors (especially elements from psychology). Moreover, our model has a specific focus on long term health consequences.

Reason's Swiss Cheese Model [113]—James Reason developed a dynamic model to describe the relationship between human factor errors and safety accidents $[114,115]$. The model provides a general categorization of human errors into slips, lapses, mistakes, and violations. This has been useful and further developed and applied into the crew resource management (CRM) framework e.g., [70], and the barrier or the bowtie method [116-119]. The limitation of the Swiss Chess model and its derivatives is the inability to explain why the human factors occur in the first place. Additionally, this class of models describes the cause of accidents as a linear sequence of events. In contrast, the RASH model offers a more detailed explanation of the psychology that underlies the human factors. It also explicitly includes the cumulative exposure and long-term health issues, whereas those other methods tend to focus on accident causation.

In summary, when compared to existing models, the RASH model has the following features. Firstly, it includes more sub-components, especially elements from psychology. Secondly, it provides an integrative treatment in the way that it relates these factors together. Thirdly, it is particularly strong at describing the cognitive processes that contribute to the decisions made before the accident commences-in contrast, many other models focus on the physical sequence of the accident. Fourthly, it specifically includes the long-term harm effects. Fifthly, the RASH model focuses on how people make risky decisions, this is a generally decision-making focus, not a specific focus on one particular situation.

\subsection{Implications for Practitioners}

The model is particularly focused on the health and chronic harm component of $\mathrm{H} \& \mathrm{~S}$, as opposed to the accident or safety part. This is deliberate, because the chronic harm part is underrepresented in the safety literature as compared to the safety part. It is much easier in industry to address the safety part, because the consequences of an accident are immediately apparent. Many of the safety systems are built on that assumption of immediacy, e.g., accident and near-miss reporting systems. Consequently, the continuous improvement processes work quickly and effectively for safety, but only weakly for long-term harm. This work makes a contribution by proposing a set of mental processes in the mind of the worker at the moment of time before the harm occurs. By framing these in terms of standard psychological constructs (many of which have their own measurement instruments) it is hoped that future work may lead to a situation where workers can be trained to put aside these 
perverse antecedents and thereby avoid chronic harm. Obviously, we have not achieved that level of intervention, but it is hoped that the model moves the field forward by providing a candidate framework for how the incidence of chronic harm may be reduced.

Our tentative recommendations to employers would be to take more care about presenting organisational alignment in a balanced way. Most chief executive officers (CEOs) are motivated, intrinsically or by performance incentives, in order to maximise worker motivation towards the organisational purpose, hence alignment. A number of SHRM tools are available to achieve this. It is rare to see the OB literature acknowledge the possibility of over-alignment and identify the specific detriments thereof. Unethical behavior is known to be one such adverse outcome, and now we propose that long-term harm is another. If this is true, then it implies the necessity to use the SHRM tools in a more balanced way, so as not to recruit perverse agency. Thus, it is our belief that the problem of perverse agency, while occurring within the cognition of the worker, is fundamentally a problem of the organization and its culture, and consequently, a deficiency of leadership.

Regarding the conventional safety prevention framework of avoidance and minimization, the implications of the present work would be the following. For avoidance, we suggest that workers judge their capability more carefully at the decision-making stage before commencing work. We suggest that they attempt to de-bias themselves from excessive organizational over-alignment-possibly they might achieve this by considering themselves as professional operators who (a) are technical experts about the task and (b) intend to live a long life with high quality of life. For minimization, we suggest achieving this aim by (a) team support and (b) safety training. Team support refers to building a support system between teammates, e.g., tool-box talks [120]. This is not solved by recruiting a new safety team, but building a positive safety culture.

\subsection{Limitations of the Work}

The work is conceptual in nature, and the proposed causality is thus speculative. We have designed the model to improve the robustness, by including extant concepts from psychology where possible. However, this does not guarantee that the model is correct.

Another limitation is that we have designed the model from a pejorative perspective, i.e., of the worker who is taking a safety short cut. There are many other workers who do not behave in this way, and the model does not represent their actions.

\subsection{Implications for Further Research}

This work provides a broad framework within which are numerous implied relationships of causality. Future work could be directed to verify whether the sub processes do actually work as depicted, and what the conditional factors (contingency variables) might be. An interesting and useful feature of the flowchart model is that each activity block can be interrogated in this way. For example, in Figure 5, it is proposed that intrinsic motivation is some combination of several factors (personality, worldview, valance, expectancy, etc.). How strong are these individual contributions? This might be explored by seeking the correlation coefficients in a quantitative statistical study. Similarly, there are opportunities for qualitative research in the sub models, for example, to determine how workers make sense of their alignment with the organizational objectives.

\section{Conclusions}

This paper developed a conceptual model for why workers expose themselves to health risks. It is proposed that harm arises from personal motivation and over-alignment with organisational purpose, which recruit misdirected creativity and perverse agency. Original contributions are the provision of a detailed explanation for risk-taking, and the integration of multiple well-established psychological constructs. 
Author Contributions: S.J. and D.P. created the RASH model and concept. All authors contributed to the refinement of the model and the writing of the paper. D.P. and J.P. provided project direction and supervision.

Conflicts of Interest: The authors declare no conflicts of interest.

\section{References}

1. Rigas, F.; Konstandinidou, M.; Centola, P.; Reggio, G.T. Safety analysis and risk assessment in a new pesticide production line. J. Loss Prev. Process Ind. 2003, 16, 103-109. [CrossRef]

2. Siu, N. Risk assessment for dynamic systems: An overview. Reliab. Eng. Syst. Saf. 1994, 43, 43-73. [CrossRef]

3. Tugnoli, A.; Khan, F.; Amyotte, P.; Cozzani, V. Safety assessment in plant layout design using indexing approach: Implementing inherent safety perspective: Part 1-Guideword applicability and method description. J. Hazard. Mater. 2008, 160, 100-109. [CrossRef] [PubMed]

4. Chander, H.; Garner, J.; Wade, C.; Knight, A. Postural control in workplace safety: Role of occupational footwear and workload. Safety 2017, 3, 18. [CrossRef]

5. Heydaryan, S.; Suaza Bedolla, J.; Belingardi, G. Safety design and development of a human-robot collaboration assembly process in the automotive industry. Appl. Sci. 2018, 8, 344. [CrossRef]

6. Roussel, S.; King, N.J. Safety Management System-Workplace Activities at Toyota Motor Manufacturing, TEXAS, Inc. In Proceedings of the ASME 2012 International Mechanical Engineering Congress and Exposition (IMECE), Houston, TX, USA, 9-15 November 2012; American Society of Mechanical Engineers: Houston, TX, USA, 2012; pp. 467-473.

7. Lind, S.; Nenonen, S.; Kivisto-Rahnasto, J. Safety risk assessment in industrial maintenance. J. Qual. Maint. Eng. 2008, 14, 205-217. [CrossRef]

8. Kaassis, B.; Badri, A. Development of a preliminary model for evaluating occupational health and safety risk management maturity in small and medium-sized enterprises. Safety 2018, 4, 5. [CrossRef]

9. Blair, E.; Seo, D.-C. Safety training. Prof. Saf. 2007, 52, 42.

10. Wogalter, M.S.; Conzola, V.C.; Smith-Jackson, T.L. Research-based guidelines for warning design and evaluation. Appl. Ergon. 2002, 33, 219-230. [CrossRef]

11. Stanton, N.A. Handbook of Human Factors and Ergonomics Methods; CRC Press: Boca Raton, FL, USA, 2005.

12. Reason, J. Human Error; Cambridge University Press: Cambridge, UK, 1990.

13. Mulcahy, M.B.; Boylan, C.; Sigmann, S.; Stuart, R. Using bowtie methodology to support laboratory hazard identification, risk management, and incident analysis. J. Chem. Health Saf. 2017, 24, 14-20. [CrossRef]

14. Ehlers, S.; Ehlers, U.C.; Ryeng, E.O.; McCormack, E.; Khan, F. Assessing the safety effects of cooperative intelligent transport systems: A bowtie analysis approach. Accid. Anal. Prev. 2017, 99, 125-141. [CrossRef] [PubMed]

15. Smith, D.; Veitch, B.; Khan, F.; Taylor, R. Understanding industrial safety: Comparing fault tree, bayesian network, and fram approaches. J. Loss Prev. Process Ind. 2017, 45, 88-101. [CrossRef]

16. Nanda, S.K.; Tripathy, D.P.; Patra, S.K. A sugeno fuzzy model for noise induced hearing loss in the mining industry. Noise Vib. Worldw. 2008, 39, 25-36. [CrossRef]

17. WHO. WHO: Occupational Health. Available online: http://www.who.int/topics/occupational_health/en/ (accessed on 7 June 2018).

18. Whittaker, J.D.; Robinson, T.; Acharya, A.; Singh, D.; Smith, M. Noise-induced hearing loss in small-scale metal industry in nepal. J. Laryngol. Otol. 2014, 128, 871-880. [CrossRef] [PubMed]

19. Bull, N. Mandatory use of eye protection prevents eye injuries in the metal industry. Occup. Med. 2007, 57, 605-606. [CrossRef] [PubMed]

20. Murray, J.; Davies, T.; Rees, D. Occupational lung disease in the south african mining industry: Research and policy implementation. J. Public Health Policy 2011, 32, S65-S79. [CrossRef] [PubMed]

21. Borton, C. Industrial Dust Diseases. Available online: www.patient.info/doctor/industrial-dust-diseases (accessed on 7 June 2018).

22. Li, Y.; Wang, H. Quantitative area risk assessment and safety planning on chemical industry parks. In Proceedings of the 2013 International Conference on Quality, Reliability, Risk, Maintenance, and Safety Engineering (QR2MSE), Chengdu, China, 15-18 July 2013; pp. 413-418. 
23. Institute of Medicine; National Research Council; Panel on Musculoskeletal Disorders and the Workplace. Musculoskeletal Disorders and the Workplace: Low Back and Upper Extremities; National Academy Press: Washington, DC, USA, 2001.

24. Bazzini, G.; Capodaglio, E.M.; Mancin, D. The shoe industry and the musculoskeletal system. G. Ital. Med. Lav. Ergon. 2012, 34, 24-28. [PubMed]

25. Dupont, J.P. Hearing Loss: Classification, Causes, and Treatment; Nova Biomedical Books: New York, NY, USA, 2011.

26. Worksafe. Worksafe New Zealand: Why Be Safe. Available online: http://manufacturing.worksafe.govt.nz/ (accessed on 7 June 2018).

27. Vroom, V. Work and Motivation; John Wiley: New York, NY, USA, 1964.

28. Renko, M.; Kroeck, K.G.; Bullough, A. Expectancy theory and nascent entrepreneurship. Small Bus. Econ. 2012, 39, 667-684. [CrossRef]

29. Guzzo, R.A. Types of rewards, cognitions, and work motivation. Acad. Manag. Rev. 1979, 4, 75-86. [CrossRef]

30. Presslee, A.; Vance, T.W.; Webb, R.A. The effects of reward type on employee goal setting, goal commitment, and performance. Account. Rev. 2013, 88, 1805-1831. [CrossRef]

31. Bénabou, R.; Tirole, J. Intrinsic and extrinsic motivation. Rev. Econ. Stud. 2003, 70, 489-520. [CrossRef]

32. Monteiro de Castro, M.L.; Reis Neto, M.T.; Ferreira, C.A.A.; Gomes, J.F.d.S. Values, motivation, commitment, performance and rewards: Analysis model. Bus. Process Manag. J. 2016, 22, 1139-1169. [CrossRef]

33. Kleinbeck, U.; Fuhrmann, H. Effects of a psychologically based management system on work motivation and productivity. Appl. Psychol. Int. Rev. 2000, 49, 596-610. [CrossRef]

34. Zheng, H.; Li, D.; Hou, W. Task design, motivation, and participation in crowdsourcing contests. Int. J. Electron. Commer. 2011, 15, 57-88. [CrossRef]

35. Alhassan, R.K.; Spieker, N.; van Ostenberg, P.; Ogink, A.; Nketiah-Amponsah, E.; de Wit, T.F.R. Association between health worker motivation and healthcare quality efforts in ghana. Hum. Resour. Health 2013, 11, 37. [CrossRef] [PubMed]

36. Solovieva, S.; Lallukka, T.; Virtanen, M.; Viikari-Juntura, E. Psychosocial factors at work, long work hours, and obesity: A systematic review. Scand. J. Work Environ. Health 2013, 39, 241-258. [CrossRef] [PubMed]

37. Princeton University “Mental Health". Available online: http://wordnetweb.princeton.edu/perl/webwn? $\mathrm{s}=$ mental+health\&sub=Search + WordNet\&o2=\&o0=1\&o8=1\&o1=1\&o7=\&o5=\&o9=\&o6=\&o3=\&o4=\&h= (accessed on 7 June 2018).

38. Westgaard, R.H.; Winkel, J. Occupational musculoskeletal and mental health: Significance of rationalization and opportunities to create sustainable production systems-A systematic review. Appl. Ergon. 2011, 42, 261-296. [CrossRef] [PubMed]

39. NZ Govt. Health and safety at Work Act 2015. Public Act 2015. Available online: http:/ /www.legislation. govt.nz/act/public/2015/0070/latest/DLM5976660.html (accessed on 7 June 2018).

40. Bevilacqua, M.; Ciarapica, F.E.; Mazzuto, G.; Paciarotti, C. Visual management implementation and evaluation through mental workload analysis. In Proceedings of the 11th IFAC Workshop on Intelligent Manufacturing Systems (IMS), Sao Paulo, Brazil, 22-24 May 2013; IFAC Secretariat: Sao Paulo, Brazil, 2013; pp. 294-299.

41. Kumudini, D.V.G.; Higuchi, Y.; Theppitak, C.; Lai, V.; Movahed, M.; Izumi, H.; Kumashiro, M. Effects of mental capacity on work ability in middle-aged factory workers: A field study. In Proceedings of the 2nd East Asian Ergonomics Federation Symposium (EAEFS), Hsinchu, Taiwan, 4-8 October 2011; CRC Press: Hsinchu, Taiwan, 2012; pp. 73-79.

42. Clarke, S.; Cooper, C.L.; Ebrary, I. Managing the Risk of Workplace Stress: Health and Safety Hazards; Routledge: London, UK; New York, NY, USA, 2004.

43. Tuarob, S.; Tucker, C.S.; Kumara, S.; Giles, C.L.; Pincus, A.L.; Conroy, D.E.; Ram, N. How are you feeling? A personalized methodology for predicting mental states from temporally observable physical and behavioral information. J. Biomed. Inform. 2017, 68, 1-19. [CrossRef] [PubMed]

44. Biron, C.; Burke, R.J. Creating Healthy Workplaces: Stress Reduction, Improved Well-Being, and Organizational Effectiveness, 2nd ed.; Gower Pub: Burlington, VT, USA, 2014.

45. Butler, D. Psychiatric injury in workplace: Direction for cases involving stress or bullying. Torts Law J. 2006, $14,124-134$. 
46. Herring, M.P.; Campbell, M.J.; Sheehan, R.B. Associations between motivation and mental health in sport: A test of the hierarchical model of intrinsic and extrinsic motivation. Front. Psychol. 2018, 9, 707.

47. Ramos, R.; Güntert, S.; Brauchli, R.; Bauer, G.; Wehner, T.; Hämmig, O. Exploring the interaction between volunteering status, paid job characteristics and quality of volunteers' motivation on mental health. VOLUNTAS Int. J. Volunt. Nonprofit Organ. 2016, 27, 790-809. [CrossRef]

48. Waters, V.L. Motivation and decision making. Okla. Nurse 2009, 54, 5-6. [PubMed]

49. Marie, L.; Ellen, M.; Bénédicte, C. Why are occupational health and safety training approaches not effective? Understanding young worker learning processes using an ergonomic lens. Saf. Sci. 2014, 68, 250-257.

50. Job, J.; Smith, D.; Safe Work Australia. Motivations, Attitudes, Perceptions and Skills:What They Said about Work Health and Safety in 2010. Available online: www.safeworkaustralia.gov.au (accessed on 9 March 2018).

51. Ozigbo, N.C. The implications of human resources management and organizational culture adoption on knowledge management practices in nigerian oil and gas industry. Commun. IIMA 2012, 12, 91-104.

52. May, D.R.; Gilson, R.L.; Harter, L.M. The psychological conditions of meaningfulness, safety and availability and the engagement of the human spirit at work. J. Occup. Organ. Psychol. 2004, 77, 11-37. [CrossRef]

53. Sauter, S.L.; Murphy, L.R.; Hurrell, J.J. Prevention of work-related psychological disorders: A national strategy proposed by the national institute for occupational safety and health (niosh). Am. Psychol. 1990, 45, 1146-1158. [CrossRef] [PubMed]

54. Reiss, S. Multifaceted nature of intrinsic motivation: The theory of 16 basic desires. Rev. Gen. Psychol. 2004, 8, 179-193. [CrossRef]

55. Higgins, D.M.; Peterson, J.B.; Pihl, R.O.; Lee, A.G.M. Prefrontal cognitive ability, intelligence, big five personality, and the prediction of advanced academic and workplace performance. J. Personal. Soc. Psychol. 2007, 93, 298-319. [CrossRef] [PubMed]

56. Rundmo, T.; Hale, A.R. Managers' attitudes towards safety and accident prevention. Saf. Sci. 2003, 41, 557-574. [CrossRef]

57. Danièle, C.; Jean-Pierre, B. Occupational health and safety management in small size enterprises: An overview of the situation and avenues for intervention and research. Saf. Sci. 2003, 41, 301-318.

58. Živković, S.; Ivanova, T. Organizational culture as one of the main factors for the successful safety management. Serbian J. Manag. 2016, 11, 69-80. [CrossRef]

59. Banerjee, A.V. A simple model of herd behavior. Q. J. Econ. 1992, 107, 797-817. [CrossRef]

60. O'Toole, M. The relationship between employees' perceptions of safety and organizational culture. J. Saf. Res. 2002, 22, 231-243. [CrossRef]

61. Pons, D.J. Pike river mine disaster: Systems-engineering and organisational contributions. Safety 2016, 2, 1-26. [CrossRef]

62. Filiz, E.; Battaglio, R.P. Personality and decision-making in public administration: The five-factor model in cultural perspective. Int. Rev. Adm. Sci. 2017, 83, 3-22. [CrossRef]

63. Goldberg, L.R. The structure of phenotypic personality traits. Am. Psychol. 1993, 48, 26-34. [CrossRef] [PubMed]

64. Beus, J.M.; Dhanani, L.Y.; McCord, M.A. A meta-analysis of personality and workplace safety: Addressing unanswered questions. J. Appl. Psychol. 2015, 100, 481-498. [CrossRef] [PubMed]

65. Richardson, M.; Abraham, C. Conscientiousness and achievement motivation predict performance. Eur. J. Personal. 2009, 23, 589-605. [CrossRef]

66. DeJoy, D.M. Theoretical models of health behavior and workplace self-protective behavior. J. Saf. Res. 1996, 27, 61-72. [CrossRef]

67. Ormrod, J.E. Educational Psychology: Developing Learners, 5th ed.; Pearson/Merrill Prentice Hall: Upper Saddle River, NJ, USA, 2006.

68. Hepler, T.J.; Feltz, D.L. Path analysis examining self-efficacy and decision-making performance on a simulated baseball task. Res. Quarterl. Exerc. Sport 2012, 83, 55-64. [CrossRef] [PubMed]

69. Hu, X.; Griffin, M.; Yeo, G.; Kanse, L.; Hodkiewicz, M.; Parkes, K. A new look at compliance with work procedures: An engagement perspective. Saf. Sci. 2018, 105, 46-54. [CrossRef]

70. Chen, C.-F.; Chen, S.-C. Measuring the effects of safety management system practices, morality leadership and self-efficacy on pilots' safety behaviors: Safety motivation as a mediator. Saf. Sci. 2014, 62, 376-385. [CrossRef] 
71. Chughtai, A.A. Creating safer workplaces: The role of ethical leadership. Saf. Sci. 2015, 73, 92-98. [CrossRef]

72. Huang, J.L.; Ford, J.K. Driving locus of control and driving behaviors: Inducing change through driver training. Transp. Res. Part F Traffic Psychol. Behav. 2012, 15, 358-368. [CrossRef]

73. Lee, C. Exploring the characteristics of organizational factors on safety climate in taiwan. In Proceedings of the 2011 International Conference on Information Technology for Manufacturing Systems (ITMS), Shanghai, China, 7-8 May 2011; Trans Tech Publications: Shanghai, China, 2011; pp. 662-667.

74. Paulhus, D.L.; Williams, K.M. The dark triad of personality: Narcissism, machiavellianism, and psychopathy. J. Res. Personal. 2002, 36, 556-563. [CrossRef]

75. Vernon, P.A.; Villani, V.C.; Vickers, L.C.; Harris, J.A. A behavioral genetic investigation of the dark triad and the big 5. Personal. Individ. Differ. 2008, 44, 445-452. [CrossRef]

76. Goodboy, A.K.; Martin, M.M. The personality profile of a cyberbully: Examining the dark triad. Comput. Hum. Behav. 2015, 49, 1-4. [CrossRef]

77. Burtverde, V.; Chraif, M.; Aniei, M.; Mihil, T. The incremental validity of the dark triad in predicting driving aggression. Accid. Anal. Prev. 2016, 96, 1-11. [CrossRef] [PubMed]

78. Kern, L.; Geneau, A.; Laforest, S.; Dumas, A.; Tremblay, B.; Goulet, C.; Lepage, S.; Barnett, T.A. Risk perception and risk-taking among skateboarders. Saf. Sci. 2014, 62, 370-375. [CrossRef]

79. Patankar, M.S.; Brown, J.P.; Treadwell, M.D. Safety Ethics: Cases from Aviation, Healthcare, and Occupational and Environmental Health; Ashgate: Aldershot, UK; Burlington, VT, USA, 2005.

80. IPENZ. IPENZ Code of Ethical Conduct. Available online: https://www.engineeringnz.org/resources/ code-ethical-conduct/2016 (accessed on 7 June 2018).

81. Schneider, B.; Gonzalez-Roma, V.; Ostroff, C.; West, M.A. Organizational climate and culture: Reflections on the history of the constructs in the journal of applied psychology. J. Appl. Psychol. 2017, 102, 468-482. [CrossRef] [PubMed]

82. Hofmann, D.A.; Burke, M.J.; Zohar, D. 100 years of occupational safety research: From basic protections and work analysis to a multilevel view of workplace safety and risk. J. Appl. Psychol. 2017, 102, 375-388. [CrossRef] [PubMed]

83. Di Fabio, A. Positive healthy organizations: Promoting well-being, meaningfulness, and sustainability in organizations. Front. Psychol. 2017, 8, 1938. [CrossRef] [PubMed]

84. Zohar, D. A group-level model of safety climate: Testing the effect of group climate on microaccidents in manufacturing jobs. J. Appl. Psychol. 2000, 85, 587-596. [CrossRef] [PubMed]

85. Tam, V.W.Y.; Fung, I.W.H. Behavior, attitude, and perception toward safety culture from mandatory safety training course. J. Prof. Issues Eng. Educ. Pract. 2012, 138, 207-213. [CrossRef]

86. Floyd, H.L. A systems safety approach to occupational electrical safety. IEEE Trans. Ind. Appl. 2015, 51, 1284-1288. [CrossRef]

87. Atombo, C.; Wu, C.Z.; Tettehfio, E.O.; Nyamuame, G.Y.; Agbo, A.A. Safety and health perceptions in work-related transport activities in ghanaian industries. Saf. Health Work 2017, 8, 175-182. [CrossRef] [PubMed]

88. Griffin, M.A.; Cordery, J.; Soo, C. Dynamic safety capability: How organizations proactively change core safety systems. Organ. Psychol. Rev. 2016, 6, 248-272. [CrossRef]

89. Kim, Y.H.; Park, J.S.; Park, M.J. Creating a culture of prevention in occupational safety and health practice. Saf. Health Work 2016, 7, 89-96. [CrossRef] [PubMed]

90. Edwards, J.R.D.; Davey, J.; Armstrong, K. Returning to the roots of culture: A review and re-conceptualisation of safety culture. Saf. Sci. 2013, 55, 70-80. [CrossRef]

91. Wu, T.C.; Li, C.C.; Shu, Y.H. Measuring safety culture in departments of electrical and electronic engineering at universities. In Proceedings of the 10th UICEE Annual Conference on Engineering Education, Bangkok, Thailand, 19-23 March 2007; pp. 229-232.

92. Dov, Z. Safety climate and beyond: A multi-level multi-climate framework. Saf. Sci. 2008, 46, $376-387$. [CrossRef]

93. Cooper, M.D.; Phillips, R.A. Exploratory analysis of the safety climate and safety behavior relationship. J. Saf. Res. 2004, 35, 497-512. [CrossRef] [PubMed]

94. Johnson, S.E. The predictive validity of safety climate. J. Saf. Res. 2007, 38, 511-521. [CrossRef] [PubMed]

95. Gyekye, S.A. Occupational safety management: The role of causal attribution. Int. J. Psychol. 2010, 45, 405-416. [CrossRef] [PubMed] 
96. Han, J.; LaMarra, D.; Vapiwala, N. Applying lessons from social psychology to transform the culture of error disclosure. Med. Educ. 2017, 51, 996-1001. [CrossRef] [PubMed]

97. Reiman, T.; Oedewald, P.; Rollenhagen, C. Characteristics of organizational culture at the maintenance units of two nordic nuclear power. Reliab. Eng. Syst. Saf. 2005, 89, 331-345. [CrossRef]

98. Reader, T.W.; O'Connor, P. The deepwater horizon explosion: Non-technical skills, safety culture, and system complexity. J. Risk Res. 2014, 17, 405-424. [CrossRef]

99. Reiman, T.; Oedewald, P. Assessment of complex sociotechnical systems-theoretical issues concerning the use of organizational culture and organizational core task concepts. Saf. Sci. 2007, 45, 745-768. [CrossRef]

100. Lindhout, P.; Reniers, G. What about nudges in the process industry? Exploring a new safety management tool. J. Loss Prev. Process Ind. 2017, 50, 243-256. [CrossRef]

101. Bandura, A. Human agency in social cognitive theory. Am. Psychol. 1989, 44, 1175-1184. [CrossRef] [PubMed]

102. Snyder, C.R.; Lopez, S.J. Handbook of Positive Psychology; Oxford University Press: New York, NY, USA, 2005.

103. Bandura, A. Self-efficacy. Harv. Ment. Health Lett. 1997, 13, 4.

104. Bandura, A. Social cognitive theory: An agentic perspective. Asian J. Soc. Psychol. 1999, 2, 21-41. [CrossRef]

105. Williams, D.M. Outcome expectancy and self-efficacy: Theoretical implications of an unresolved contradiction. Personal. Soc. Psychol. Rev. 2010, 14, 417-425. [CrossRef] [PubMed]

106. Hewson, M. Encyclopedia of Case Study Research; SAGE Publications, Inc.: Thousand Oaks, CA, USA, 2012; pp. 13-16.

107. Judge, T.A.; Jackson, C.L.; Shaw, J.C.; Scott, B.A.; Rich, B.L. Self-efficacy and work-related performance: The integral role of individual differences. J. Appl. Psychol. 2007, 92, 107-127. [CrossRef] [PubMed]

108. Zinn, J.O. The meaning of risk-taking key concepts and dimensions. J. Risk Res. 2017, 1-15. [CrossRef]

109. Herkowitz, H.N. The International Society for Study of the Lumbar Spine. In The Lumbar Spine, 3rd ed.; Lippincott Williams \& Wilkins: Philadelphia, PA, USA, 2004.

110. Üstün, T.B. Measuring Health and Disability: Manual for Who Disability Assessment Schedule Whodas 2.0; World Health Organization: Geneva, Switzerland, 2010.

111. Stone, R.W. Industrial accident prevention. H. W. Heinrich. Soc. Serv. Rev. 1931, 5, 323-324. [CrossRef]

112. Abdelhamid, T.S.; Everett, J.G. Identifying root causes of construction accidents. J. Constr. Eng. Manag. 2000, 126, 52-60. [CrossRef]

113. Reason, J. Human error: Models and management. BMJ 2000, 320, 768-770. [CrossRef] [PubMed]

114. Perneger, T.V. The swiss cheese model of safety incidents: Are there holes in the metaphor? BMC Health Serv. Res. 2005, 5, 71. [CrossRef] [PubMed]

115. Bonsu, J. A systems approach to mining safety: An application of the swiss cheese model. J. S. Afr. Inst. Min. Metall. 2016, 116, 776-784. [CrossRef]

116. De Ruijter, A.; Guldenmund, F. The bowtie method: A review. Saf. Sci. 2016, 88, 211-218. [CrossRef]

117. Hale, A.R.; Ale, B.J.M.; Goossens, L.H.J.; Heijer, T.; Bellamy, L.J.; Mud, M.L.; Roelen, A.; Baksteen, H.; Post, J.; Papazoglou, I.A.; et al. Modeling accidents for prioritizing prevention. Reliab. Eng. Syst. Saf. 2007, 92, 1701-1715. [CrossRef]

118. Kanes, R.; Ramirez Marengo, M.C.; Abdel-Moati, H.; Cranefield, J.; Vechot, L. Developing a framework for dynamic risk assessment using bayesian networks and reliability data. J. Loss Prev. Process Ind. 2017, 50, 142-153. [CrossRef]

119. McLeod, R.W. Human factors in barrier management: Hard truths and challenges. Process Saf. Environ. Prot. 2017, 110, 31-42. [CrossRef]

120. Royle, D. Making process safety personal. In Proceedings of the Hazards 27, Birmingham, UK, 10-12 May 2017; Institution of Chemical Engineers: Birmingham, UK, 2017.

(C) 2018 by the authors. Licensee MDPI, Basel, Switzerland. This article is an open access article distributed under the terms and conditions of the Creative Commons Attribution (CC BY) license (http:/ / creativecommons.org/licenses/by/4.0/). 